\title{
Pulmonary arterial hypertension caused by congenital extrahepatic portocaval shunt: a case report
}

\author{
Kai-yang Lin, Hui Chen and Ling Yu (D)
}

\begin{abstract}
Background: Congenital extrahepatic portocaval shunt (CEPS), also known as Abernethy malformation, is an extremely rare anomaly of the splanchnic venous system, especially when accompanied by pulmonary arterial hypertension.
\end{abstract}

Case presentation: We report a case of a 15-year-old female who was diagnosed with CEPS (Abernethy type lb) accompanied by pulmonary arterial hypertension. This case was incidentally identified during abdominal ultrasound examination and confirmed by mesenteric and splenic arteriography. During more than 4 years of follow-up, after receiving sildenafil $(80 \mathrm{mg} /$ day), the patient's condition improved in the first year after discharge. However, one year later, the patient's conditions start to deteriorate.

Conclusion: This article presents a rare case of Abernethy malformation accompanied by pulmonary arterial hypertension, which can be diagnosed by using abdominal ultrasonography, portal vein computed tomography angiography or mesenteric and splenic arteriography. This malformation had limited treatment and poor prognosis.

Keywords: Abernethy malformation, Congenital extrahepatic portocaval shunt, Pulmonary arterial hypertension

\section{Case report}

Congenital extrahepatic portocaval shunt (CEPS) is a congenial anomaly observed predominantly in females in which splanchnic blood bypasses the liver and drains directly into the inferior vena cava (IVC) [1]. Since the first description by Abernethy in 1793 [2], fewer than 100 cases of CEPS have been reported, and only a few cases accompanied by pulmonary hypertension have been described [3-7]. Here, we present a case of CEPS with pulmonary arterial hypertension in a female adolescent patient.

A 15-year-old female was admitted to our department with shortness of breath. One year prior to admission, she started to feel shortness of breath when walking fast. One month before admission, she suffered from nasal congestion, rhinorrhoea, and cough. On admission, the patient had severe dyspnoea (New York Heart Association, NYHA class IV). In addition, physical examination

\footnotetext{
* Correspondence: yuling4321@126.com

Department of Cardiology, Fujian Provincial Hospital, Fujian Medical University, Fujian Cardiovascular Institute, Fuzhou 350001, China
}

showed a systolic murmur heard loudest in the second left intercostal space, peripheral oedema, and splenomegaly.

Laboratory tests showed a decrease in platelet count $\left(55 \times 10^{\wedge} 9 / \mathrm{L}\right.$; reference range, $\left.125-350\right)$ and serum albu$\min (30 \mathrm{~g} / \mathrm{L}$; reference range, 40-55) and an increasement in bilirubin $(12.3 \mu \mathrm{mol} / \mathrm{L}$; reference range, $0.0-5.1)$. Electrocardiogram (ECG) revealed right axis deviation, right ventricular hypertrophy and T-wave changes in precordial leads. The echocardiography also showed enlargement of the pulmonary artery and its branches (Fig. 1a). Additionally, both the right atrium (RA) and right ventricle (RV) were significantly dilated (the inner diameters of RA and RV were $4.9 \mathrm{~cm}$ and $4.1 \mathrm{~cm}$, respectively, measured in the four chamber view), and the RV wall thickness was increased $(0.99-1.12 \mathrm{~cm})$ (Fig. 1b). The estimated RV systolic pressure (RVSP) was $97 \mathrm{mmHg}$, which calculated from the maximal velocity of tricuspid regurgitation,.Right catheterization was performed to further evaluate the pulmonary arterial pressure, demonstrating right atrial pressure (RAP) of $17 / 4 / 9 \mathrm{mmHg}$, right ventricular pressure (RVP) of $104 / 40 / 62 \mathrm{mmHg}$, pulmonary capillary wedge pressure (PCWP) of $11 / 2 / 7 \mathrm{mmHg}$, pulmonary arterial

(c) The Author(s). 2019 Open Access This article is distributed under the terms of the Creative Commons Attribution 4.0 International License (http://creativecommons.org/licenses/by/4.0/), which permits unrestricted use, distribution, and 


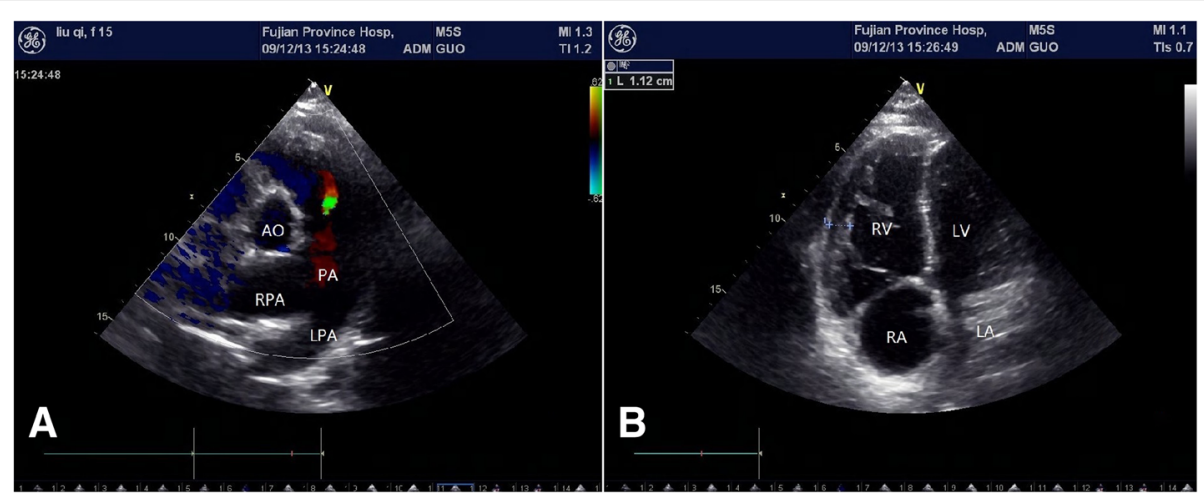

Fig. 1 Echocardiography shows an enlargement of the PA and its branches (a). Both RA and RV are significantly dilated, and the RV wall thickness is increased (b). PA: pulmonary artery; RPA: right pulmonary artery; LPA: left pulmonary artery; AO: aorta; RA: right atrium; RV: right ventricle; LA: left atrium; LV: left ventricle

pressure (PAP) of 105/43/64 mmHg, pulmonary vascular resistance (PVR) of 12.63 woodU and a cardiac index (CI) of $2.44 \mathrm{~L} / \mathrm{min} / \mathrm{m}^{2}$.

Incidentally, abdominal ultrasonography revealed the absence of an intrahepatic portal vein system and a tortuous and dilated splenic vein (Fig. 2a, b). Further evaluation using computed tomography angiography (CTA) of the portal vein demonstrated the absence of a portal vein and dilation of the splenic vein (SV), while the superior mesenteric vein (SMV) was connected to the left renal vein (LRV) through a large number of collateral vessels that drained directly into the IVC bypass the liver (Fig. 3a). CT also revealed heterogeneous density lesions in the liver nodules, tortuous and dilated left renal and splenic veins, and enlargement of the spleen (Fig. 3b). Mesenteric and splenic arteriography were performed to confirm the diagnosis. In the delayed phase, the portal vein was absent, but the shunt between the splenic and renal venous supply and the left renal vein and inferior vena cava was observed (Fig. 4a, b).
Based on the findings described above, we established a diagnosis of Abernethy malformation (type $\mathrm{Ib}$ ) with pulmonary arterial hypertension. The patient refused surgical treatment and received sildenafil $(80 \mathrm{mg} /$ day). Her conditions were improved, and she was discharged on day 12 . After discharge, the patient was subject to follow-up clinical visits. During the first year after discharge, the patient's symptoms (such as shortness of breath and fatigue) were improved significantly. With continuous use of sildenafil, however, the patient's symptoms (such as shortness of breath and fatigue) were aggravated, and the related parameters of echocardiography were also worsening at one year later (Fig. 5).

\section{Discussion and conclusions}

CEPS is a rare congenital anomaly caused by the abnormal embryonic development of the portal vein. CEPS is also known as the Abernethy malformation because it was first reported by John Abernethy in 1793 in an autopsy of a 10-month-old infant who died of unknown

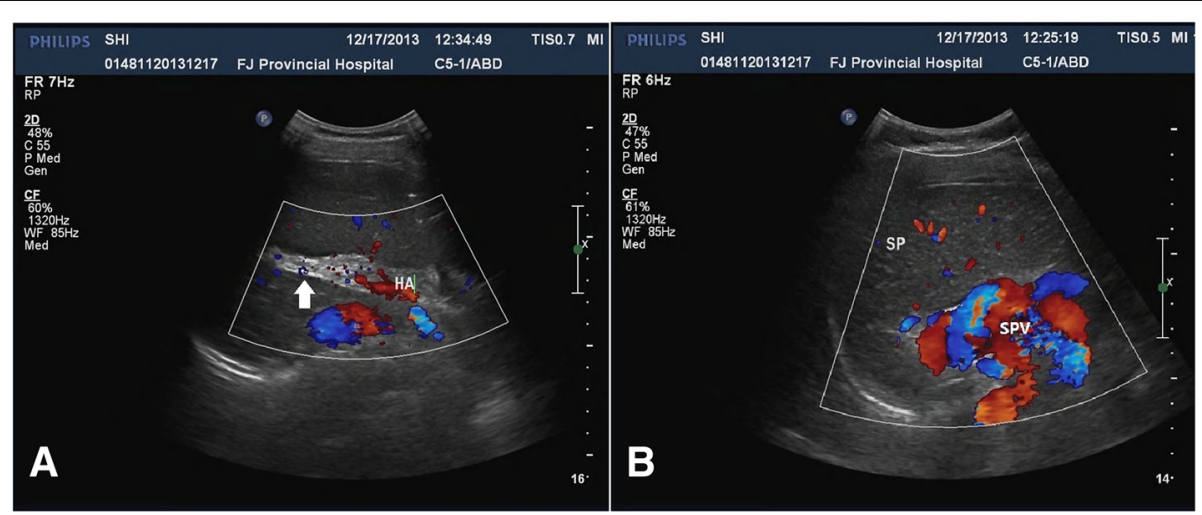

Fig. 2 Abdominal ultrasonography shows that the intrahepatic PV system is absent (arrows) (a), and the SPV is tortuous and dilated (b). PV: portal vein; HA: hepatic artery; SP: spleen; SPV: splenic vein 


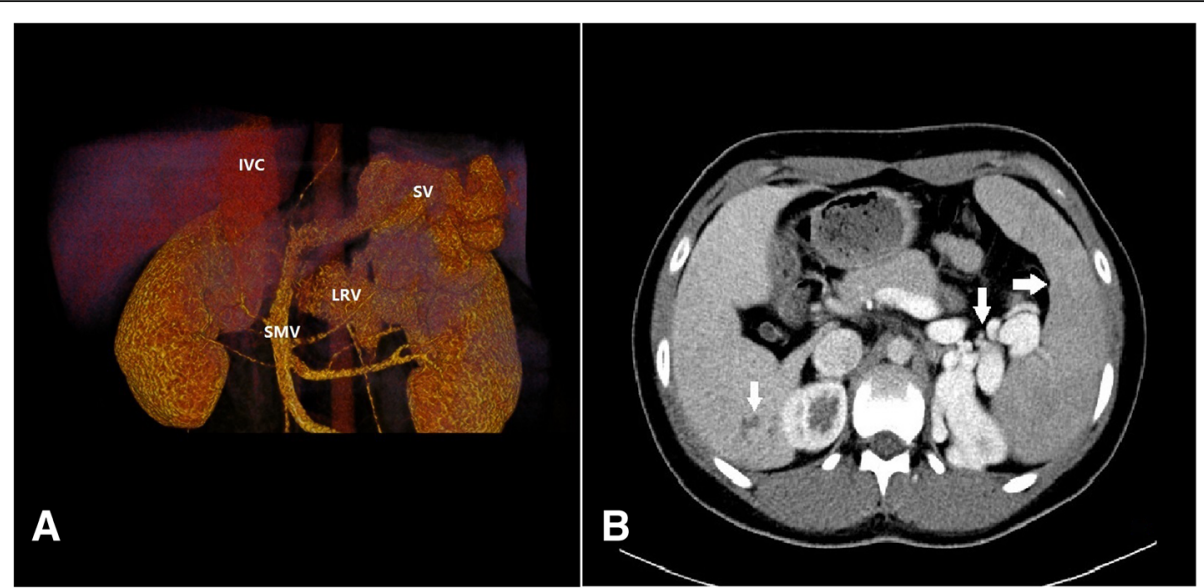

Fig. 3 PV-CTA shows that the trunk and branches of PV are absent, the SV is widened, with the SMV joining the LRV and then draining directly into the IVC without passing through the liver (a). CTA also reveals the enlargement of the spleen and splenic veins (arrows) and heterogeneous density lesions in the liver nodules (arrows) (b). PV: portal vein; CTA: computed tomography angiography; SV: splenic vein; SMV: superior mesenteric vein; LRV: left renal vein; IVC: inferior vena cava

reasons [2]. In 1994, Morgan and Superina [8] classified CEPS into two types based on the presence or absence of an intrahepatic portal venous supply. Type I is characterized by the absence of the intrahepatic PV with complete diversion of portal blood into system veins (end-to-side shunts). Type I is further subdivided into two subtypes: (i) separate drainage of the superior mesenteric and splenic veins into the IVC, iliac veins, or renal veins (Ia); and (ii) superior mesenteric and splenic veins are joined to form a short extrahepatic PV that drains into the IVC (Ib). Type II is characterized by the presence of a hypoplastic portal vein with portal blood diversion into the vena cava through side-to-side, extrahepatic communication.

Under normal conditions, portal venous blood carrying nutrients drains into the hepatic vein through the liver sinusoidal system and then returns to the inferior vena cava. In CEPS, as a lack of hepatic portal vein perfusion or hypoperfusion, nutrients and active substances absorbed by the gastrointestinal tract enter systemic circulation, directly bypassing the liver and leading to a series of pathophysiological changes and clinical syndromes. The clinical presentations of CEPS may vary and depend on associated conditions: (1) liver dysfunction and hepatic neoplasms, which may be benign (focal nodular hyperplasia and nodular regenerative hyperplasia) or malignant (liver cancer), may be due to the lack of perfusion and nutrient delivery to the liver [9-11]. (2) Congenital hepatic shunts can also present together with hepatic encephalopathy, hepatopulmonary syndrome [12], and hypoglycaemia [13]. (3) Increased pressure of the splenic vein and superior mesenteric vein system with complete or partial occlusion of the portal vein can lead to hypersplenism and haemorrhage of the digestive tract. (4) Congenital extrahepatic portosystemic shunts are frequently associated with other anomalies, including

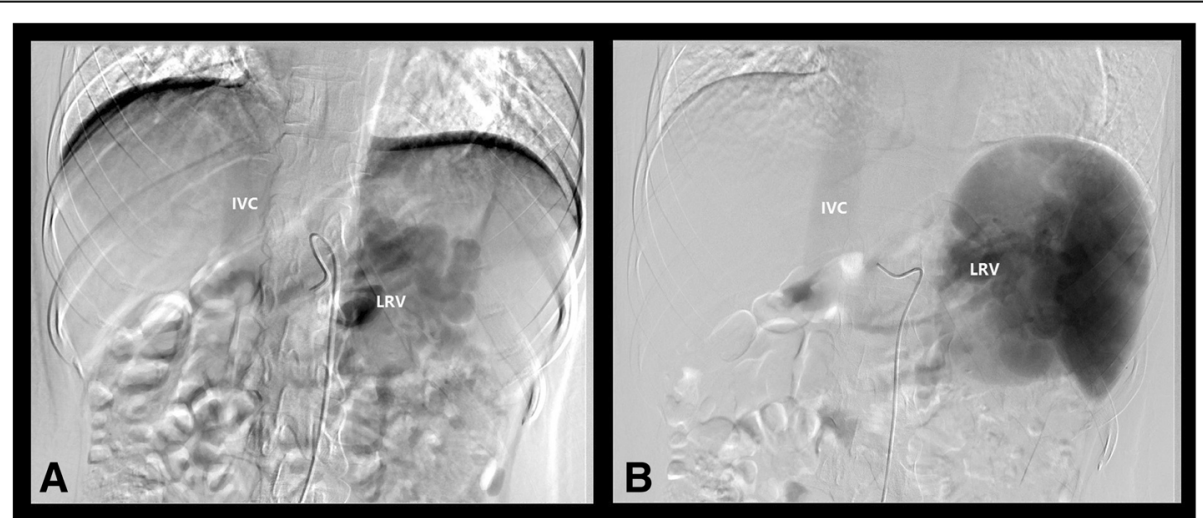

Fig. 4 Mesenteric and splenic arteriography shows that the portal vein was absent, and the shunt between splenic and renal venous supply and the LRV and IVC can be seen in the delayed phase $(\mathbf{a}, \mathbf{b})$. LRV: left renal vein; IVC: inferior vena cava 


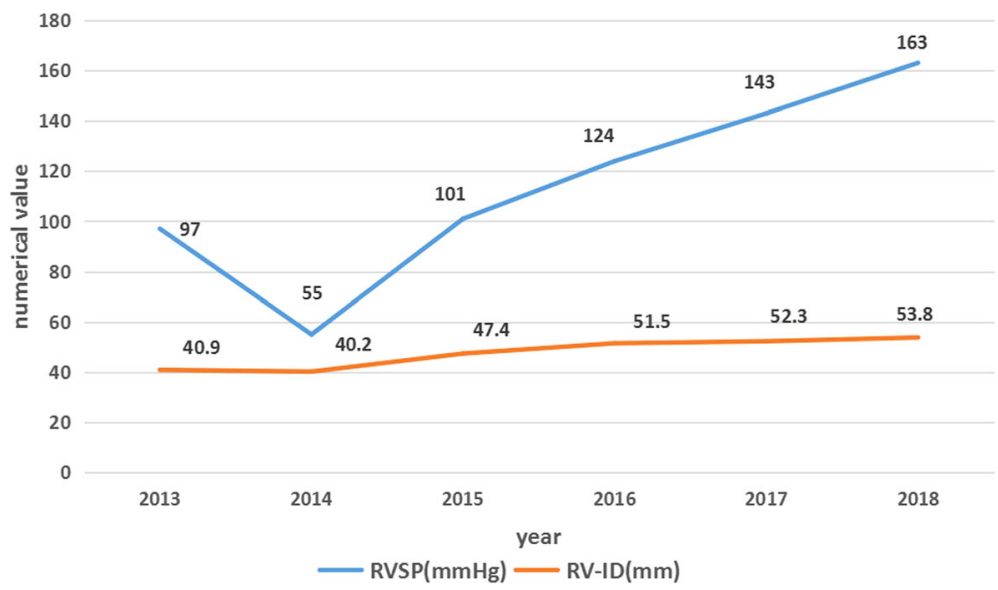

Fig. 5 Changes in important parameters in echocardiography. RVSP: right ventricle systolic pressure; RA: right atrium; RV-ID: right ventricle inner diameter

congenital heart disease, polysplenia, biliary atresia, malrotation, duodenal atresia, annular pancreas, situs inversus, renal tract anomalies, and skeletal anomalies [14]. Type I Abernethy malformation frequently occurs in children and females and is often associated with other malformations and complications, such as congenital heart disease, polysplenia, biliary atresia, hepatic encephalopathy, and hepatopulmonary syndrome. Type II Abernethy malformation is more common in males and is rarely associated with the above malformations [14].

It is difficult to diagnose Abernethy malformation based on the clinical presentations only. The image characteristics of this disease are portal venous malformation, in which the trunk and branches of the portal vein are absent or atretic. Angiography is the gold standard for the diagnosis of CEPS but is not the first imaging study commonly employed because it is an invasive examination that may not identify other visceral lesions at the same time [15]. Non-invasive cross-sectional imaging techniques, such as ultrasound, CT or MRI can be used as the first choice for diagnosis, which can also show the shunt and intrahepatic portal vein branches.

To our knowledge, CEPS is rarely reported as a case associated with pulmonary arterial hypertension. In our case, we incidentally found portal atresia by abdominal ultrasound examination, which was then confirmed by portal vein CTA and mesenteric and splenic arteriography. Finally, we diagnosed the patient with Abernethy malformation (type Ib) according to the imaging findings, which showed the absence of a portal vein and the joining of the superior mesenteric veins with the splenic veins.

Pulmonary hypertension develops in approximately $2 \%$ of patients with portal hypertension [16], which is called portopulmonary hypertension (PPHT). The pathogenesis of pulmonary hypertension caused by CEPS may be interpreted as PPHT, which includes the following [17]. First, this condition is caused by an imbalance between vasoconstrictors and vasodilators promoting pulmonary vasoconstriction. Second, the hyperdynamic circulation contributes to the development of pulmonary hypertension. Third, the increased pulmonary blood flow may produce excessive shear stress that leads to endothelial injury and dysfunction with vasoconstriction and progressive vascular remodelling. Finally, the vasoconstrictive and proliferative substances that bypass the liver without metabolism, reach the pulmonary vascular bed directly and act on pulmonary vasculature may lead to pulmonary hypertension.

Unfortunately, there is still no unified experience or consensus in the treatment of Abernethy malformation [14]. The treatment plan is dependent on the type of shunt and the individual conditions. Treatment for CEPS usually includes medications and surgery. For patients with type I CEPS who develop severe complications, such as encephalopathy, hepatopulmonary syndrome, pulmonary hypertension or neoplasms, liver transplantation and portal vein reconstruction appear to be the best treatment options. Patients with type II CEPS with portal hypertension and hepatic encephalopathy can benefit from early shunt occlusion surgery $[14,18,19]$.

\section{Abbreviations}

CEPS: Congenital extrahepatic portocaval shunt; IVC: Inferior vena cava; PV: Portal vein; SPV: Splenic vein

\section{Acknowledgements}

Not applicable.

Authors' contributions

$K Y L$ performed data analyses and wrote the manuscript. $L Y$ and $H C$ conducted the clinical diagnosis and data collection. All authors read and approved the final manuscript. 


\section{Funding}

The authors did not receive any funding for this manuscript.

\section{Availability of data and materials}

All data generated or analysed during the study are included in the published article.

\section{Ethics approval and consent to participate}

No ethics approval was required in this case.

\section{Consent for publication}

Written informed consent was obtained from the patient and her parents for publication of this case report and the accompanying images. A copy of the written consent form is available for review by the Editor of this journal.

\section{Competing interests}

The author(s) declare no potential conflicts of interest with respect to the research, authorship, and/or publication of this case report.

Received: 9 January 2019 Accepted: 2 June 2019

Published online: 13 June 2019

\section{References}

1. Howard ER, Davenport M. Congenital extrahepatic portocaval shunts--the Abernethy malformation. J Pediatr Surg. 1997:32(3):494-7.

2. Abernethy J. Account of two instances of uncommon formation in the viscera of the human body: from the Philosophical Transactions of the Royal Society of London. Med Facts Obs. 1797;7:100-8.

3. Zhang XL, Duan XM, Wang FY, Zhang X, Sun Y, Ma N, Du ZD. An infant with Abernethy malformation associated with Heterotaxy and pulmonary hypertension. Chin Med J. 2017;130(18):2257-8.

4. Yi JE, Jung HO, Youn HJ, Choi JY, Chun HJ, Lee JY. A case of pulmonary arterial hypertension associated with congenital extrahepatic portocaval shunt. J Korean Med Sci. 2014:29(4):604-8.

5. Hori T, Yonekawa Y, Okamoto S, Ogawa K, Ogura Y, Oike F, Takada Y, Egawa $\mathrm{H}$, Nguyen $\mathrm{JH}$, Uemoto S. Pediatric orthotopic living-donor liver transplantation cures pulmonary hypertension caused by Abernethy malformation type Ib. Pediatr Transplant. 2011;15(3):e47-52

6. lida T, Ogura Y, Doi H, Yagi S, Kanazawa H, Imai H, Sakamoto S, Okamoto S, Uemoto S. Successful treatment of pulmonary hypertension secondary to congenital extrahepatic portocaval shunts (Abernethy type 2) by living donor liver transplantation after surgical shunt ligation. Transpl Int. 2010; 23(1):105-9.

7. Ohno T, Muneuchi J, Ihara K, Yuge T, Kanaya Y, Yamaki S, Hara T. Pulmonary hypertension in patients with congenital portosystemic venous shunt: a previously unrecognized association. Pediatrics. 2008;121(4):e892-9.

8. Morgan G. Superina R. Congenital absence of the portal vein: two cases and a proposed classification system for portasystemic vascular anomalies. J Pediatr Surg. 1994;29(9):1239-41.

9. Chandler TM, Heran MK, Chang SD, Parvez A, Harris AC. Multiple focal nodular hyperplasia lesions of the liver associated with congenital absence of the portal vein. Magn Reson Imaging. 2011;29(6):881-6.

10. Lisovsky M, Konstas AA, Misdraji J. Congenital extrahepatic portosystemic shunts (Abernethy malformation): a histopathologic evaluation. Am J Surg Pathol. 2011;35(9):1381-90.

11. Benedict M, Rodriguez-Davalos M, Emre S, Walther Z, Morotti R. Congenita extrahepatic portosystemic shunt (Abernethy malformation type Ib) with associated hepatocellular carcinoma: case report and literature review. Pediatr Dev Pathol. 2017;20(4):354-62.

12. Ding $X Y$, Chen $F$, Zhao $X X, W u H$, Chen SP, Qin $Y W$. A rare cause of cyanosis: hepatopulmonary syndrome caused by congenital extrahepatic portosystemic shunt. Case Rep Vasc Med. 2011;2011:508171.

13. Senniappan S, Pitt K, Shah P, Arya V, Jaiswal S, Haddad M, Hind J, Dhawan A, Davenport M, Hussain K. Postprandial hyperinsulinaemic hypoglycaemia secondary to a congenital portosystemic shunt. Horm Res Paediatr. 2015; 83(3):217-20.

14. Franchi-Abella S, Branchereau S, Lambert V, Fabre M, Steimberg C, Losay J, Riou JY, Pariente D, Gauthier F, Jacquemin E, et al. Complications of congenital portosystemic shunts in children: therapeutic options and outcomes. J Pediatr Gastroenterol Nutr. 2010;51(3):322-30.
15. Alonso-Gamarra E, Parrón M, Pérez A, Prieto C, Hierro L, López-Santamaría M. Clinical and radiologic manifestations of congenital extrahepatic portosystemic shunts: a comprehensive review. Radiographics. 2011;31(3): 707-22.

16. Hervé $P$, Lebrec $D$, Brenot $F$, Simonneau G, Humbert M, Sitbon O, Duroux $P$. Pulmonary vascular disorders in portal hypertension. Eur Respir J. 1998;11(5): 1153-66.

17. Raevens S, Geerts A, Van Steenkiste C, Verhelst X, Van Vlierberghe H, Colle I. Hepatopulmonary syndrome and portopulmonary hypertension: recent knowledge in pathogenesis and overview of clinical assessment. Liver Int. 2015:35(6):1646-60.

18. Sanada Y, Urahashi T, Ihara Y, Wakiya T, Okada N, Yamada N, Egami S, Hishikawa S, Kawano Y, Ushijima K, et al. The role of operative intervention in management of congenital extrahepatic portosystemic shunt. Surgery. 2012;151(3):404-11.

19. Shinkai M, Ohhama Y, Nishi T, Yamamoto H, Fujita S, Take H, Adachi M, Tachibana K, Aida N, Kato K, et al. Congenital absence of the portal vein and role of liver transplantation in children. J Pediatr Surg. 2001;36(7):1026-31.

\section{Publisher's Note}

Springer Nature remains neutral with regard to jurisdictional claims in published maps and institutional affiliations.
Ready to submit your research? Choose BMC and benefit from:

- fast, convenient online submission

- thorough peer review by experienced researchers in your field

- rapid publication on acceptance

- support for research data, including large and complex data types

- gold Open Access which fosters wider collaboration and increased citations

- maximum visibility for your research: over $100 \mathrm{M}$ website views per year

At BMC, research is always in progress.

Learn more biomedcentral.com/submissions 